\title{
Composição Bromatológica e Produção de Efluente de Silagens de Capim-Tanzânia sob Efeitos do Emurchecimento, do Tamanho de Partícula e do Uso de Aditivos Biológicos ${ }^{1}$
}

\author{
Daniele Rebouças Santana Loures ${ }^{2}$, Luiz Gustavo Nussio ${ }^{3}$, Solidete de Fátima Paziani ${ }^{2}$, André \\ de Faria Pedroso ${ }^{4}$, Lucas José Mari ${ }^{5}$, José Leonardo Ribeiro ${ }^{5}$, Maity Zopollatto ${ }^{5}$, Patrick \\ Schmidt $^{5}$, Marta Coimbra Junqueira ${ }^{5}$, Irineu Umberto Packer ${ }^{3}$, Fábio Prudêncio de Campos ${ }^{6}$
}

RESUMO - O presente trabalho foi conduzido para se avaliar o efeito do emurchecimento, da redução do tamanho das partículas e da adição de enzimas fibrolíticas (com ou sem inoculante bacteriano Lactobacillus plantarum) sobre a composição bromatológica da silagem e a produção de efluente em silagens de capim-tanzânia (Panicum maximum Jacq. cv. Tanzânia). A forragem foi cortada aos 45 dias de crescimento vegetativo e armazenada em silos experimentais (50 L) durante 136 dias. O efluente foi coletado e quantificado no $1^{\circ} \stackrel{\circ}{2} \stackrel{\circ}{\circ}, 7 \stackrel{\circ}{ }, 14^{\circ} \stackrel{\circ}{ }, 21^{\circ}, 60^{\circ}, 90^{\circ}$ e $136^{\circ}$ dias de armazenamento. A adição de enzimas fibrolíticas, associadas ou não ao inoculante bacteriano, promoveu redução da fração fibrosa (FDN, FDA, celulose e hemicelulose), que foi mais acentuada nas silagens emurchecidas. Contudo, não houve aumento da digestibilidade in vitro da MS com a adição de enzimas fibrolíticas. Embora tenha havido diferenças no tamanho de partícula, a amplitude alcançada não foi suficiente para provocar alterações significativas na composição química e no efluente das silagens. Observou-se que a quantidade total de efluente produzida foi maior (250L/t forragem ensilada) em silagens não-emurchecidas e esporádica nas emurchecidas. A adição de enzimas com ou sem inoculante bacteriano não aumentou as perdas por efluente. Os valores médios de DBO (11.289 mg/L), DQO (36.279 mg/L), DQO/DBO (3,35), pH (4,9) e de sólidos totais (34.395 mg/L) e sólidos totais fixos $(16.533 \mathrm{mg} / \mathrm{L})$ foram observados no efluente das silagens não-emurchecidas. As silagens não-emurchecidas apresentaram efluente com elevado potencial poluidor para o meio ambiente.

Palavras-chave: conservação, ensilagem, enzimas, gramíneas tropicais, perdas

\section{Chemical Composition and Effluent Yield of Tanzaniagrass Silages Affected by Wilting, Particle Size and Enzymatic/Microbial Additive}

\begin{abstract}
The present trial aimed to evaluate the effects of wilting (wet vs. wilted), particle size reduction (small vs. large) and the addition of fibrolytic enzymes (alone vs. combined with Lactobacillus plantarum) on the chemical composition and effluent yield of Tanzaniagrass silages (Panicum maximum Jacq. cv. Tanzania). The forage was harvested and cut at 45-day vegetative re-growth period and stored in the experimental plastic silos (50 L) during 136 days. During the storage period, the effluent flow was collected and measured at days 1, 2, 7, 14, 21, 60, 90 and 136. The addition of fibrolytic enzymes exclusively or combined with Lactobacillus plantarum led to decreased contents of NDF, ADF, cellulose and hemicellulose, mainly on wilted silages; however, no benefit was observed in the in vitro DM digestibility. Even though particles sizes were different, the range observed was not wide enough to show significant differences either on chemical composition or effluent yield in silages. The effluent yield was higher (250L/t ensiled forage) for the wet silages and sporadical for the wilted silages. The addition of fibrolytic enzymes exclusively or combined with Lactobacillus plantarum did not increase the effluent losses. Mean values for BOD (11,289 mg/L), COD (36,279 mg/L) and COD/BOD ratio (3.35) were observed on the effluent of wet silages. Wet silages resulted in higher of pollution to the environment.
\end{abstract}

Key Words: conservation, ensilage, enzymes, losses, tropical grass

\section{Introdução}

A adição de enzimas fibrolíticas na ensilagem de gramíneas perenes tem sido proposta como estratégia para incrementar a disponibilidade de carboidratos solúveis e contribuir de forma efetiva para o aumento das fermentações da silagem e do rúmen (Beauchemin et al., 2002; Muck \& Kung Jr., 1997). Recentemente, os inoculantes enzimáticos têm recebido considerável atenção, por proporcionarem melhores resultados no desempenho de animais (Nussio et al., 1997; Beauchemin et al., 1998; Lewis et al., 1999).

\footnotetext{
${ }^{1}$ Parte da tese de Doutorado apresentada à USP/ESALQ pela primeira autora, financiada pela FAPESP

2 Doutor em Agronomia - Ciência Animal e Pastagens - USP/ESALQ. Av Pádua Dias, 11 - CEP: 13418-900-Piracicaba-SP (dloures@terra.com.br).

${ }^{3}$ Professor do Departamento de Zootecnia da USP/ESALQ. Av Pádua Dias, 11- CEP: 13418-900 - Piracicaba -SP.

${ }^{4}$ Pesquisador da EMBRAPA - Pecuária Sudeste, São Carlos - SP.

${ }^{5}$ Aluno de Pós-Graduação - Ciência Animal e Pastagens - USP/ESALQ. Av Pádua Dias, 11- CEP: 13418-900 - Piracicaba - SP.

${ }^{6}$ Pesquisador do Instituto de Zootecnia - Nova Odessa - SP.
} 
Segundo Muck \& Kung Jr. (1997), em experimentos com enzimas fibrolíticas, são apresentados resultados relativos à redução da fração fibrosa em silagens, aumento nas degradabilidades da matéria seca (MS) e da fibra em detergente neutro (FDN), incremento na produção e no teor de gordura do leite e elevação na taxa de ganho de peso em bovinos. Contudo, em determinadas situações, a escassez de resultados positivos quanto à adição de enzimas fibrolíticas em silagens pode ser atribuída ao tipo de forragem, ao método de aplicação das enzimas, ao tempo requerido para as enzimas atuarem sobre o material, ao teor de MS da forragem e ao $\mathrm{pH}$ ou à temperatura da digesta no trato animal (Beauchemin et al., 2002).

$\mathrm{O}$ teor de MS da forragem merece destaque por influenciar de forma significativa nos resultados obtidos pela utilização das enzimas fibrolíticas (Feng et al., 1992). Segundo Beauchemin et al. (2002), a aplicação de enzimas em forragens com maior teor de MS favorece a formação de um complexo enzimaforragem com grande estabilidade, que eleva a eficiência das enzimas fibrolíticas.

O processamento mecânico da forragem pode alterar sua fermentação, dependendo da extensão dos danos no tecido vegetal (Woolford, 1984; Aguiar et al., 2001). Assim, a redução do tamanho de partícula poderia ser favorável ao processo de fermentação, por facilitar a compactação da massa ensilada. De acordo com McDonald et al. (1991), o tamanho de partícula inferior a $20-30 \mathrm{~mm}$ pode favorecer a disponibilidade de carboidratos solúveis (CS) e, conseqüentemente, estimular o crescimento das bactérias láticas. No entanto, a redução do tamanho de partícula da forragem, associada ao maior grau de compactação, pode contribuir para aumentar as perdas por efluente em forragens com menor teor de MS (Loures, 2000; Nussio et al., 2002; Igarasi, 2002). A produção de efluente representa perdas de valor nutricional e risco de poluição ambiental, que podem ser evitados com a utilização de forragens emurchecidas. Embora não sejam utilizados com o objetivo de reduzir perdas por efluente, os aditivos biológicos aplicados em silagens apresentam resultados contraditórios, podendo ser tanto relatos de redução ou ausência de efeito (Haigh, 1999; Igarasi, 2002), como de aumento (Jones \& Jones, 1995; Jaster, 1995) da produção de efluente.

Os inoculantes bacterianos podem ser adicionados durante a ensilagem visando aumentar a população de bactérias desejáveis, estimular a fermentação lática e reduzir o $\mathrm{pH}$. Sua associação com enzimas fibrolíticas é recomendada por potencializar a fermentação das silagens, pois estas fornecem carboidratos solúveis para bactérias láticas (Muck \& Kung Jr., 1997).

Objetivou-se, com este experimento, avaliar o efeito da adição de enzimas fibrolíticas, associadas ou não ao inoculante bacteriano, em silagens de capimtanzânia (Panicum maximum Jacq. cv Tanzânia) com umidade original ou emurchecida e com diferentes tamanhos de partículas sobre a composição bromatológica de silagens e as perdas por efluente.

\section{Material e Métodos}

Este trabalho foi desenvolvido no Departamento de Zootecnia da Escola Superior de Agricultura "Luiz de Queiroz" (USP/ESALQ). A ensilagem do capimtanzânia aos 45 dias de crescimento vegetativo foi realizada em fevereiro de 2002. Os tratamentos impostos à forragem, no intuito de se avaliar os efeitos de tamanho de partícula, de emurchecimento e de adição de enzimas fibrolíticas, combinadas ou não com o inoculante bacteriano, estão descritos na Tabela 1 .

$\mathrm{Na}$ colheita da forragem, utilizou-se um equipamento de corte com $2 \mathrm{~m}$ de largura, com 42 facas móveis no rotor colhedor e 10 facas em sistema de disco no rotor repicador, determinando-se o tamanho de partículas pela regulagem de distanciamento das facas e contrafacas do rotor repicador da máquina. Para determinar a amplitude de variação no tamanho médio de partículas da forragem colhida e das silagens, foi realizada a avaliação da estratificação de partículas segundo adaptação da metodologia das peneiras seqüenciais do "Penn State Particle Size Separator", proposta por Lammers et al. (1996), definindo-se a porcentagem de material de diâmetro superior a $38 \mathrm{~mm}$ (peneira 1), intermediário de 38 a $19 \mathrm{~mm}$ (peneira 2) e de 19 a $7,9 \mathrm{~mm}$ (peneira 3) e inferior a 7,9 $\mathrm{mm}$. Constatou-se que na forragem a diferença de amplitude no tamanho médio das partículas maiores $(5,94 \mathrm{~cm})$ e menores $(2,84 \mathrm{~cm})$ foi de $3,1 \mathrm{~cm}$, refletindo a exploração máxima de variação na regulagem oferecida pelo equipamento quando em condições otimizadas.

A avaliação do efeito de teor de MS constou da comparação entre as silagens contendo umidade original (ensilada imediatamente após o corte) ou emurchecida (com um período de secagem no campo de cinco horas). 
Tabela 1 - Composição química e pH do capim-tanzânia para a produção de silagem Table 1 - Chemical composition and $\mathrm{pH}$ of Tanzaniagrass for silage production

\begin{tabular}{|c|c|c|c|c|c|c|}
\hline \multirow[t]{2}{*}{$\begin{array}{l}\text { Variável } \\
\text { Variable }\end{array}$} & \multicolumn{3}{|c|}{$\begin{array}{l}\text { Forragem úmida } \\
\text { Wet forage }\end{array}$} & \multicolumn{3}{|c|}{$\begin{array}{l}\text { Forragem emurchecida } \\
\text { Wilted forage }\end{array}$} \\
\hline & ENZ(-) & $\operatorname{ENZ}(+)$ & ENZ+B & ENZ(-) & $\mathrm{ENZ}(+)$ & $\mathrm{ENZ}+\mathrm{B}$ \\
\hline $\mathrm{MS}^{1}, \%$ (DM basis,\%) & 15,65 & 16,50 & 18,10 & 26,35 & 25,95 & 24,90 \\
\hline \multirow[t]{2}{*}{$\mathrm{pH}$} & 6,07 & 6,11 & 6,10 & 6,34 & 6,26 & 6,31 \\
\hline & \multicolumn{6}{|c|}{$\begin{array}{c}\text { Valores em \% MS } \\
\% \text { DM values }\end{array}$} \\
\hline $\mathrm{PB}^{2}(C P)$ & 6,00 & 5,68 & 5,99 & 6,85 & 6,45 & 6,88 \\
\hline $\mathrm{FDN}^{3}(N D F)$ & 70,35 & 72,05 & 72,75 & 71,95 & 72,05 & 71,45 \\
\hline $\operatorname{FDA}^{4}(A D F)$ & 39,85 & 40,25 & 40,65 & 40,60 & 41,30 & 42,20 \\
\hline Celulose & 34,00 & 34,95 & 35,15 & 35,65 & 36,05 & 35,85 \\
\hline \multicolumn{7}{|l|}{ Cellulose } \\
\hline Hemicelulose & 30,00 & 31,80 & 32,10 & 31,50 & 30,75 & 28,30 \\
\hline \multicolumn{7}{|l|}{ Hemicellulose } \\
\hline Lignina (Lignin) & 3,51 & 3,70 & 4,12 & 3,77 & 4,01 & 4,41 \\
\hline $\mathrm{CS}^{5}(S C)$ & 6,26 & 6,21 & 5,53 & 3,92 & 4,72 & 4,65 \\
\hline DIVMS $^{6}$ & 69,65 & 70,20 & 70,60 & 66,65 & 68,65 & 68,40 \\
\hline \multicolumn{7}{|l|}{$I V D D M$} \\
\hline Cinza (Ash) & 11,20 & 10,35 & 10,40 & 10,70 & 11,15 & 11,70 \\
\hline
\end{tabular}

ENZ (-) = sem enzimas fibrolíticas ( without fibrolytic enzymes), ENZ (+) = com enzimas fibrolíticas ( with fibrolytic enzymes); ENZ+B = com enzimas fibrolíticas mais inoculante bacteriano (with fibrolytic enzymes plus bacterial inoculant).

${ }^{1}$ Matéria seca (Dry matter), ${ }^{2}$ Proteína bruta (Crude protein), ${ }^{3}$ Fibra em detergente neutro (Neutral detergent fiber) ${ }^{4}$ Fibra em detergente ácido (Acid detergent fiber), ${ }^{5}$ Carboidratos solúveis (Soluble carbohydrates), ${ }^{6}$ Digestibilidade in vitro da matéria seca (In vitro dry matter digestibility).

Durante o processo de ensilagem, foram aplicados $150 \mathrm{~g}$ da preparação enzimática diluídos em $100 \mathrm{~L}$ de água bidestilada, e $2 \mathrm{~L}$ dessa solução por tonelada de massa verde de capim picado, representando uma taxa de aplicação de $2 \mathrm{~mL} / \mathrm{kg}$ de forragem. O inoculante bacteriano utilizado foi caracterizado por cepa de Lactobacillus plantarum e foi aplicado por aspersão, segundo recomendação técnica, com adição de $10^{11}$ UFC viáveis por tonelada de massa verde de forragem.

O material ensilado foi acondicionado em 48 tambores plásticos, com volume de $50 \mathrm{~L}$ cada, dispostos em bancadas de madeira. Na porção superior, os silos foram devidamente vedados com tampas de madeira e sacos plásticos e, em sua parte inferior, foram instaladas mangueiras conectadas a garrafas de plástico, para a drenagem do efluente. Os silos experimentais, após sua pesagem, foram submetidos à determinada coluna de pressão, utilizando-se blocos de concretos, com o objetivo de simular a pressão existente em silos de maior escala, como descrito por O'Donnell et al. (1997), em estudos para avaliação de efluentes em silagens. A carga de pressão aplicada em cada silo foi calculada considerando-se as dimensões dos tambores de $50 \mathrm{~L}$ (60 cm de altura, $34,5 \mathrm{~cm}$ de diâmetro, área de $0,094 \mathrm{~m}^{2}$ e volume de $0,056 \mathrm{~m}^{3}$ ) e o peso médio dos blocos de concreto $(9,75 \mathrm{~kg})$. Para o cálculo, foi utilizado como parâmetro um silo trincheira hipotético com base maior $(4,25 \mathrm{~m})$ e base menor (3,25 m), $2 \mathrm{~m}$ de altura e espessura de corte diário de $0,5 \mathrm{~m}$, gerando volume de $3,75 \mathrm{~m}^{3}$. Assim, para tratamentos com silagem sem emurchecimento, foi considerada densidade de $600 \mathrm{~kg} / \mathrm{m}^{3}$ para se obter pressão de $1.385 \mathrm{~kg} / \mathrm{m}^{2}$. Multiplicando essa pressão pela área do tambor e subtraindo o peso da própria silagem, obteve-se o peso (96 kg) que deveria ser aplicado sobre os tambores. Portanto, para os tratamentos de silagens nãoemurchecidas, foram necessários 10 blocos de concretos por silo. Ao longo dos dias de armazenamento, com a pesagem dos silos, o número de blocos foi alterado conforme necessário, com o intuito de se manter constante a pressão desejada. O mesmo procedimento foi adotado para os tratamentos de silagem emurchecida, porém a densidade estabelecida foi alterada para $400 \mathrm{~kg} / \mathrm{m}^{3}$ e os valores de pressão, peso da coluna de concreto e número de blocos passaram para $923 \mathrm{~kg} / \mathrm{m}^{2}, 64 \mathrm{~kg}$ e 7 blocos, respectivamente.

O efluente foi coletado, sempre às $10 \mathrm{~h}$ da manhã,

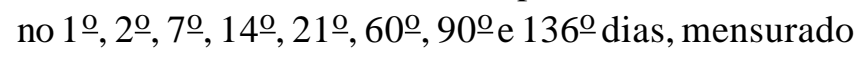


e armazenado em congelador e geladeira, para análises subseqüentes. Juntamente com a coleta do efluente, foi realizada a pesagem dos silos. O volume do efluente foi mensurado a cada 12 horas na primeira

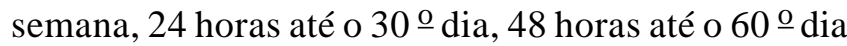
e 72 horas até a abertura dos silos.

Após os 136 dias de armazenamento, foram realizadas as amostragens das silagens, para posteriores análises bromatológicas. As amostras da forragem ensilada e das silagens armazenadas foram submetidas às seguintes determinações: FDN e fibra em detergente ácido (FDA), segundo Van Soest et al. (1991); MS, de acordo com Silva (1990); e matéria mineral (MM), conforme AOAC (1990). A determinação do $\mathrm{N}$ foi obtida pelo método de Dumas (Wiles et al., 1998) e a lignina, pelo método LDA (lignina em detergente ácido), com uso de solução de ácido sulfúrico a $72 \%$, após a determinação de FDA, empregando-se o equipamento "Daisy Incubator Ankon". Com esse equipamento, determinou-se a digestibilidade in vitro da matéria seca (DIVMS), conforme Holden (1999). Para as análises de carboidratos solúveis e de nitrogênio amoniacal, foram preparados extratos aquosos da silagem, conforme Kung Jr. et al. (1984), e armazenados em congelador. Posteriormente, para carboidratos solúveis, foi utilizada a metodologia proposta por Dubois et al. (1956) e, para nitrogênio amoniacal, adotou-se o método colorimétrico, descrito por Okuda et al. (1965). A determinação da condutividade elétrica (CE) da silagem para quantificação da intensidade de rompimento celular foi realizada de acordo com Kraus et al. (1997).

O efluente foi analisado para verificação da demanda bioquímica de oxigênio (DBO) e da demanda química de oxigênio (DQO), segundo o protocolo da APHA (1995); as análises de pH, sólidos totais (MS) e sólidos totais fixos (cinza) foram realizadas segundo Silva (1977).

As variáveis MS, PB (proteína bruta), CS, MM, FDN, FDA, lignina e DIVMS (digestibilidade in vitro da matéria seca) da silagem foram avaliadas para cada tamanho de partícula, teor de MS e aditivos, adotando-se o delineamento inteiramente casualizado em arranjo fatorial $2 \times 2 \times 3$, com quatro repetições, empregando-se o procedimento GLM, com suas médias testadas pela opção PDIFF do SAS (2000). Adotou-se como covariável para a análise das silagens a composição bromatológica da forragem (PB, CS, MM, FDN, FDA, lignina e DIVMS). As variáveis
DBO, DQO, DQO/DBO, pH, sólidos totais e sólidos totais fixos foram analisadas como parcelas repetidas no tempo, pelo procedimento MIXED do SAS. Os dados foram interpretados estatisticamente por meio de análise de variância e os modelos escolhidos basearam-se no coeficiente de determinação, a 1, 5 e $10 \%$ de probabilidade pelo teste $\mathrm{F}$.

\section{Resultados e Discussão}

$\mathrm{Na}$ avaliação do percentual de material retido nas peneiras (Tabela 2) foi constatada diferença significativa $(\mathrm{P}<0,05)$ para teor de MS e tamanho de partícula. A diferença de amplitude no tamanho médio das partículas maiores $(4,7 \mathrm{~cm})$ e menores $(3,9 \mathrm{~cm})$ das silagens foi de $0,81 \mathrm{~cm}$, inferior à expectativa inicial, considerando-se os dados previamente observados na estratificação de partículas da forragem, na época do estabelecimento dos tratamentos. Em todas as peneiras testadas, houve diferença significativa $(\mathrm{P}<0,05)$ para estratificação entre as partículas maiores e menores das silagens. As variáveis relativas à composição química e fermentação das silagens, com exceção do pH (Tabela 3), não foram alteradas em função de tamanhos de partículas.

Tabela 2 - Retenção percentual de partículas das silagens de capim-tanzânia, utilizando-se o método adaptado do "Penn State Particle Size Separator"

Table 2 - Percentage of particle retention of Tanzaniagrass silage tested with the adapted "Penn State Particle Size Separator" methodology

\begin{tabular}{lcccc}
\hline $\begin{array}{l}\text { Variável } \\
\text { Variable }\end{array}$ & \multicolumn{4}{c}{$\begin{array}{c}\text { \% Retenção } \\
\text { \% Retention }\end{array}$} \\
\cline { 2 - 5 } & $>38 \mathrm{~mm}$ & $38-19 \mathrm{~mm}$ & $19-7,9 \mathrm{~mm}$ & $<7,9 \mathrm{~mm}$ \\
\hline $\begin{array}{l}\text { Partícula menor } \\
\text { Small particle }\end{array}$ & $55,8^{\mathrm{b}}$ & $24,0^{\mathrm{a}}$ & $15,1^{\mathrm{b}}$ & $4,6^{\mathrm{b}}$ \\
$\begin{array}{l}\text { Partícula maior } \\
\text { Large particle }\end{array}$ & $59,8^{\mathrm{a}}$ & $16,5^{\mathrm{b}}$ & $16,3^{\mathrm{a}}$ & $6,5^{\mathrm{a}}$ \\
$\begin{array}{l}\text { Silagem úmida } \\
\text { Wet silage }\end{array}$ & $58,8^{\mathrm{a}}$ & $21,5^{\mathrm{a}}$ & $14,6^{\mathrm{b}}$ & $4,7^{\mathrm{b}}$ \\
$\begin{array}{l}\text { Emurchecida } \\
\text { Wilted silage }\end{array}$ & $56,8^{\mathrm{b}}$ & $18,9^{\mathrm{b}}$ & $16,8^{\mathrm{a}}$ & $6,4^{\mathrm{a}}$ \\
CV(\%) & 3,74 & 16,07 & 6,96 & 5,20 \\
\hline
\end{tabular}

$C V=$ coeficiente de variação (coefficient of variation).

Médias na coluna seguidas de letras distintas diferem $(P<0,05)$ pelo teste Tukey.

Means in the same column with unlike superscripts differ $(P<.05)$, by Tukey test. 


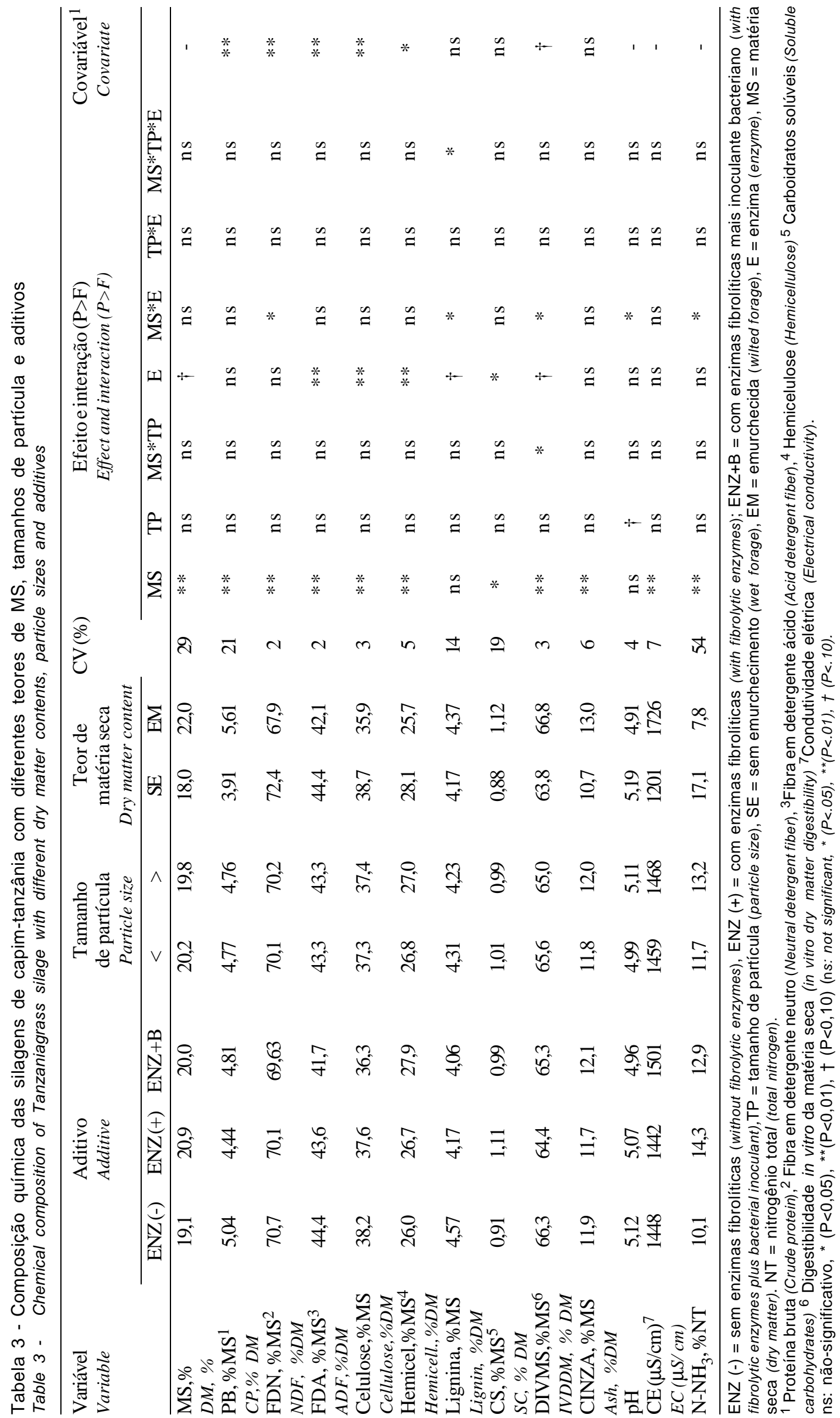


Na comparação relativa ao emurchecimento (Tabela 2), também foi observada diferença significativa $(\mathrm{P}<0,05)$ entre os tamanhos de partículas em todas as peneiras testadas. Nas silagens emurchecidas, apesar da maior dificuldade de picagem da forragem em tamanhos menores, houve maior facilidade de estratificação das partículas entre as peneiras, com menor retenção naquelas com orifícios de maior diâmetro (>19 mm). No caso da comparação entre os aditivos testados, não há explicação razoável para alteração na estratificação das partículas das silagens.

A composição bromatológica das silagens encontra-se na Tabela 3. Apesar de as condições para o emurchecimento da forragem terem sido limitadas, em função da incidência de chuvas na época da realização do experimento em campo, o teor de MS de 25,71\% pode ser considerado satisfatório na comparação entre as silagens. A elevação de $9 \%$ no teor de MS da forragem em cinco horas de exposição à desidratação resultou no aumento médio de $1,8 \%$ por hora.

Neste estudo, não foi verificada influência significativa $(\mathrm{P}>0,10)$ do tamanho de partícula sobre a condutividade elétrica, observando-se média de $1.463 \mu \mathrm{S} / \mathrm{cm}$. A mensuração da condutividade elétrica do material em análise, expressa em $\mu \mathrm{S} / \mathrm{cm}$, avalia a intensidade da ruptura celular da forragem submetida ao corte e o consequiente extravasamento de íons para a solução (Kraus et al., 1997).

A inclusão de enzimas fibrolíticas ou de sua associação com inoculante bacteriano não alterou $(\mathrm{P}>0,10)$ a condutividade elétrica das silagens, sugerindo que a adição de enzimas fibrolíticas e de enzimas associadas ao inoculante bacteriano não provocou aumento da lise das células vegetais em silagens de gramíneas tropicais. Contudo, verificou-se, em silagens emurchecidas, que a condutividade elétrica aumentou de 1.201 para $1.726 \mu \mathrm{S} / \mathrm{cm}$ em relação às silagens não-emurchecidas.

Para o teor de MS das silagens, verificou-se que houve diferença $(\mathrm{P}<0,05)$ entre os tratamentos com silagens emurchecidas e não-emurchecidas ( 22 vs. $18 \%$ de MS) e efeito $(\mathrm{P}<0,10)$ de enzimas. Nas silagens nãoemurchecidas, ensiladas logo após o corte, o aumento no teor de MS era previsto, por haver maior drenagem de efluente, provocando aumento da concentração dos componentes da MS, em relação à composição original da forragem. Contudo, foi constatado efeito contrário para as silagens emurchecidas, pois, em relação à MS da forragem emurchecida original, houve redução de 25,7 para $22 \%$. Esse efeito pode ser atribuído, em parte, à água, como produto resultante dos processos de respiração, fermentação e oxidação que ocorrem dentro do silo (Woolford, 1984).

Para o teor de PB, foi verificado efeito de emurchecimento $(\mathrm{P}<0,01)$; as silagens nãoemurchecidas apresentaram menor teor de PB que as silagens emurchecidas, redução que foi mais acentuada ao se comparar com a forragem original.

O emurchecimento está normalmente relacionado ao aumento do potencial osmótico da massa ensilada (Moser, 1995), o que favorece a proliferação de microrganismos desejáveis e diminui a extensão da fermentação. A evidência do efeito do emurchecimento no processo de conservação da forragem (Tabela 3) revelou-se pelo maior teor de carboidratos solúveis remanescentes $(\mathrm{P}<0,05)$ e pelo menor teor de nitrogênio amoniacal $(\mathrm{P}<0,01)$ nas silagens emurchecidas.

Quanto à fração fibrosa, tanto para FDN como para FDA, celulose e hemicelulose, com exceção da lignina, verificou-se efeito significativo $(\mathrm{P}<0,01)$ do teor de MS. As silagens obtidas de forragem emurchecida apresentaram os menores teores de fração fibrosa. Segundo Levitt (1980), a perda de água na planta determina o aumento na concentração de ácido abcísico, responsável pelo fechamento dos estômatos e pela elevação da concentração de etileno que induziria a síntese de beta-1,4 endoglucanase. Esse cenário poderia ter sido acentuado com a adição das enzimas fibrolíticas durante a ensilagem (Mandebvu et al., 1998, 1999). Foram verificados valores médios para FDN de 71,55 e 71,82\% na MS para forragem fresca e para forragem emurchecida, enquanto suas respectivas silagens apresentaram teores médios de 72,38 e 67,89\% de FDN.

Observou-se efeito da adição das enzimas fibrolíticas sobre a fração fibrosa, com diferença significativa para FDA, celulose, hemicelulose $(\mathrm{P}<0,01)$ e lignina $(\mathrm{P}<0,10)$. $\mathrm{Na}$ análise da FDN, houve apenas efeito $(\mathrm{P}<0,05)$ da interação do teor de MS e das enzimas. De acordo com Van Soest (1994), a fração FDN da forragem nem sempre é reduzida na silagem tratada com enzimas. A adição de enzimas fibrolíticas em silagens emurchecidas proporcionou maior eficácia na redução do teor de FDN, quando comparada à adição de enzimas fibrolíticas associadas ao inoculante bacteriano.

Nas silagens não-emurchecidas (Tabela 3), houve aumento da concentração de $\operatorname{FDN}(\mathrm{P}<0,01)$, o que 
pode ter ocorrido por causa das perdas por efluente, especialmente de componentes do conteúdo celular. Além disso, o desaparecimento de carboidratos fermentescíveis, contidos originalmente na forragem, pode favorecer a elevação do teor de FDN (Mahanna, 1993) como efeito de concentração. Houve redução $(\mathrm{P}<0,01)$ no teor de hemicelulose independentemente do teor de MS, sendo mais acentuada nas silagens emurchecidas. A partir dos resultados obtidos, sugere-se que a intensidade da ação das enzimas fibrolíticas na degradação da fração fibrosa está mais associada ao teor de MS.

Para a DIVMS, foram constatadas diferenças significativas para os efeitos de teor de MS ( $\mathrm{P}<0,01)$, de interação teor de MS e tamanho de partícula, de interação teor de MS e enzimas $(\mathrm{P}<0,05)$ e para o efeito de enzimas $(\mathrm{P}<0,10)$. A maior DIVMS em silagens emurchecidas pode ser atribuída, em parte, ao fato de estas silagens apresentarem menor fração fibrosa. Observou-se redução $(\mathrm{P}<0,05)$ do teor de lignina somente em silagens emurchecidas tratadas com inoculante e enzimas fibrolíticas, porém, não houve aumento significativo da digestibilidade da MS, reforçando a hipótese de que nem sempre a concentração de lignina é a única responsável pelas limitações da digestibilidade (Jung \& Allen,1995).

Observou-se efeito significativo $(\mathrm{P}<0,05)$ da adição de enzimas fibrolíticas e do teor de MS sobre os teores de carboidratos solúveis, que foram maiores nas silagens emurchecidas com adição exclusiva de enzimas (média de 1,22\% na MS). No entanto, verificaram-se menores valores de carboidratos solúveis na composição original das forragens emurchecidas (Tabela 1). Segundo Moser (1995), uma das principais alterações durante o emurchecimento corresponderia às perdas de carboidratos solúveis e ácidos orgânicos provocadas pela respiração da forragem. Esse efeito, em parte, poderia estar associado à maior intensidade de degradação da fração FDN observada nesses tratamentos. Nadeau et al. (2000) constataram aumento na concentração de açúcares à medida que se elevou a quantidade de celulase adicionada à silagem de alfafa (Medicago sativa L.) e Dactylis glomerata L. Muck \& Kung Jr. (1997) sugeriram que a adição de enzimas fibrolíticas poderia proporcionar incrementos ao padrão de fermentação da silagem, favorecendo a degradação de carboidratos estruturais da forragem, por fornecer açúcar adicional para a fermentação.

Entretanto, neste experimento, a digestibilidade não foi superior nem houve redução da fração de nitrogênio amoniacal nas silagens com enzimas.

Para o $\mathrm{pH}$, houve efeito $(\mathrm{P}<0,05)$ da interação teor de MS e enzimas e do tamanho de partícula $(\mathrm{P}<0,10) . \mathrm{Na}$ análise do nitrogênio amoniacal, foi verificado efeito $(\mathrm{P}<0,01)$ do teor de $\mathrm{MS}$ e da interação MS e enzimas $(\mathrm{P}<0,05)$. Somente o $\mathrm{pH}$ respondeu à alteração no tamanho de partícula; as silagens com partículas menores apresentaram maior acidez. Igarasi (2002), avaliando o tamanho de partícula, verificou efeito significativo para $\mathrm{pH}$, de modo que as silagens com menor tamanho apresentaram valores de $\mathrm{pH}$ inferiores aos daquelas com partículas maiores (4,39 vs. 4,50). Resultados similares foram encontrados por Aguiar et al. (2001), também com silagem de capim-tanzânia.

Para nitrogênio amoniacal, por meio do desdobramento da interação teor de MS e enzimas, verificouse que as silagens emurchecidas produziram menor teor de nitrogênio amoniacal que as não-emurchecidas.

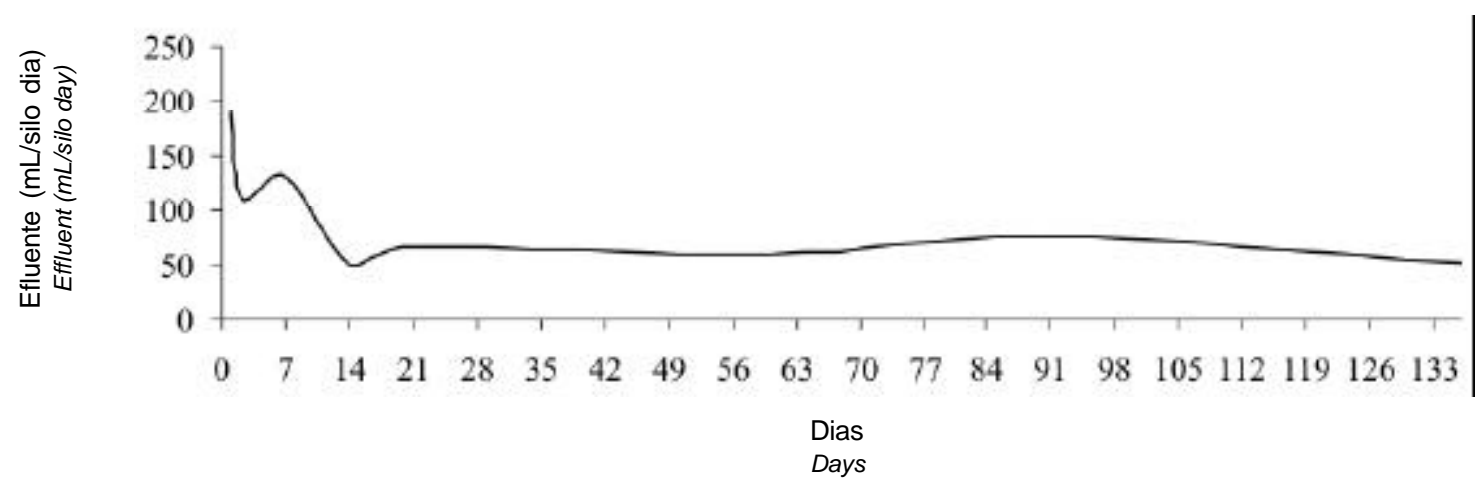

Figura 1 - Quantidade diária de efluente observada $(\mathrm{mL})$ em um período de 136 dias de armazenamento, em silagens de capim-tanzânia não-emurchecido.

Figure 1 - Observed daily effluent yield $(\mathrm{mL})$ during 136 days of storage, in wet Tanzaniagrass silages. 
Os menores teores de nitrogênio amoniacal foram obtidos com a adição de enzimas fibrolíticas somente em silagens emurchecidas.

$\mathrm{Na}$ análise da produção de efluente, considerou-se somente o resultado das silagens não-emurchecidas, uma vez que não foi verificada produção de efluente nos primeiros 90 dias nas silagens emurchecidas. Nestas últimas, somente após 90 dias de armazenamento, foi observada produção esporádica e pouco expressiva de efluente em alguns tratamentos.

Verificou-se que, nessas condições experimentais, mais de $80 \%$ do total de efluente foi produzido após a primeira semana de coleta. Observou-se, ainda, que o pico de fluxo da produção de efluente ocorreu no primeiro dia de ensilagem (Figura 1). Loures (2000) constatou, em silagens de capim-elefante, pico de fluxo no segundo dia de armazenamento. Talvez essa diferença na produção inicial esteja relacionada à alteração da integridade estrutural e ao tempo em que se inicia a fermentação das forragens ensiladas (Pitt \& Parlange, 1987; Greenhill, 1964).

$\mathrm{Na}$ análise da quantidade de efluente produzida durante os 136 dias não foi verificado efeito do tamanho de partícula, da adição de enzimas ou de interações. No entanto, foi constatado efeito $(\mathrm{P}<0,01)$ do teor de MS sobre a produção de efluente. Observou-se que a quantidade total média de efluente produzida foi de $8,7 \mathrm{~L}$ (250L/t de forragem ensilada), em silagens não-emurchecidas, e de $94 \mathrm{~mL}$, nas emurchecidas (3L/t de forragem ensilada). A produção de efluente é diretamente proporcional à umidade da forragem ensilada, encontrando-se na literatura muitas equações que podem ser utilizadas para sua estimação (Castle \& Watson, 1973; Bastiman, 1976; Rotz et al., 1993).

Os valores médios de DBO (11.289 mg/L), DQO (36.279 mg/L), DQO/DBO (3,35), pH (4,9), sólidos totais $(34.395 \mathrm{mg} / \mathrm{L})$ e sólidos totais fixos $(16.533 \mathrm{mg} / \mathrm{L})$, durante o período de armazenamento, encontram-se dentro da amplitude aceita para efluente de silagens de gramíneas (Tabela 4). Mesmo sendo inferiores àqueles reportados em diversos artigos (Galanos et al., 1995; Loures et al., 2003), ainda assim representa um alto valor, visto que a legislação brasileira estabelece valores máximos de DBO e DQO de 60 e 90 mg/ $\mathrm{L}$, respectivamente, para os esgotos e dejetos lançados em cursos de água ou rios (COPAM, 1986; FEAM, 1998).

Em relação aos dados obtidos para a DBO, houve efeito $(\mathrm{P}<0,01)$ do período de armazenamento (dias); para DQO, houve efeito $(\mathrm{P}<0,10)$ da interação entre dias e enzimas $(\mathrm{P}<0,10)$ e a razão $\mathrm{DQO} / \mathrm{DBO}$ apresentou efeito $(\mathrm{P}<0,01)$ de enzimas e período de armazenamento. Tanto DBO quanto DQO são variáveis importantes na análise do conteúdo de matéria orgânica em esgotos domésticos. Segundo Silva (1977), a DBO é definida como a quantidade de oxigênio necessária para estabilizar a matéria orgânica, por

Tabela 4 - Composição do efluente das silagens de capim-tanzânia com diferentes teores de MS, tamanho de partícula e aditivos

Table 4 - Chemical composition of effluent from Tanzaniagrass silages with different dry matter content, particle size and additives

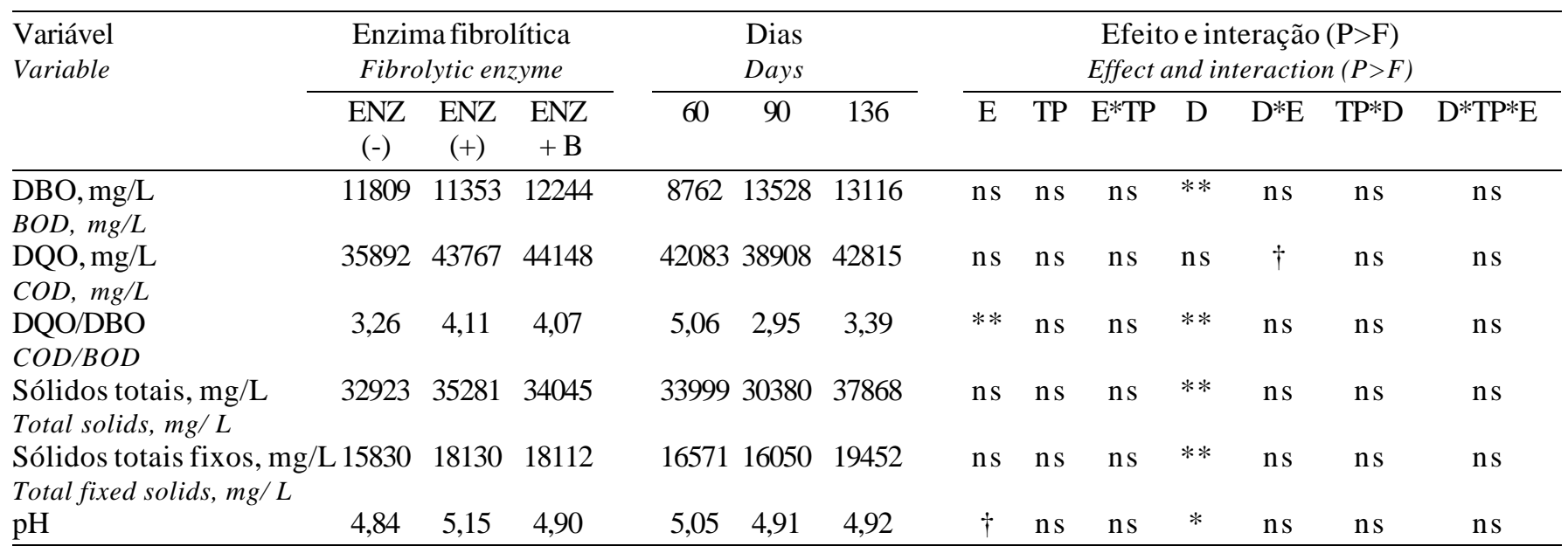

ENZ (-) = sem enzimas fibrolíticas (without fibrolytic enzymes), ENZ $(+)=$ com enzimas fibrolíticas (with fibrolytic enzymes); ENZ+B = com enzimas fibrolíticas mais inoculante bacteriano (with fibrolytic enzymes plus bacterial inoculant), TP = tamanho de partícula (particle size), $\mathrm{E}=$ enzima (enzyme), $\mathrm{D}=$ dia (day).

ns: não-significativo, ${ }^{*}(\mathrm{P}<0,05),{ }^{* *}(\mathrm{P}<0,01), \dagger(\mathrm{P}<0,10)$ (ns: not significant, ${ }^{*}(P<.05),{ }^{* *}(P<.01), \dagger(P<.10)$ 
microrganismos aeróbios mantidos em temperatura e período de tempo determinados e a DQO, como a quantidade de oxigênio necessária para estabilizar a matéria orgânica, por meio da utilização de um forte oxidante, como o dicromato de potássio.

O efluente de silagens, que é rico em matéria orgânica e serve como fonte de alimento para esses microrganismos, apresentará maior demanda de oxigênio por exaurir de forma significativa o oxigênio do meio. Braile \& Cavalcanti (1993) consideram como resíduo facilmente biodegradável aquele cuja relação DQO/DBO é menor que 2, recomendando-se o tratamento biológico convencional. Entretanto, relação DQO/DBO maior que 2 indica a existência de matéria orgânica não-biodegradável, devendo, portanto, ser imposto tratamento físico-químico. Verificou-se, neste experimento, independentemente do período avaliado, que o tratamento biológico, a princípio, não seria recomendado. A adição de enzimas, associadas ou não ao inoculante bacteriano, não contribuiu para aumentar o potencial poluidor do efluente das silagens.

\section{Conclusões}

A adição de enzimas fibrolíticas nas silagens promoveu redução da fração fibrosa, principalmente de hemicelulose, tanto em silagens emurchecidas quanto nas não-emurchecidas; sua eficiência foi mais acentuada em silagens emurchecidas, apesar de não ter havido aumento na DIVMS.

As perdas por efluente foram maiores nas silagens de capim-tanzânia não-emurchecidas, que apresentaram elevado potencial poluidor. Todavia, não houve aumento na produção de efluente na presença de enzimas fibrolíticas associadas ou não ao inoculante bacteriano nessas silagens.

\section{Agradecimento}

À Fundação de Amparo à Pesquisa do Estado de São Paulo, pelo apoio financeiro ao projeto e pela concessão de bolsas de estudo.

\section{Literatura Citada}

AGUIAR, R.N.S.; CRESTANA, R.F.; NUSSIO, L.G. et al. Efeito do tamanho de partícula na composição da fração nitrogenada de silagem de capim Tanzânia. In: REUNIÃO ANUAL DA SOCIEDADE BRASILEIRA DE ZOOTECNIA, 38., 2001, Piracicaba. Anais... Piracicaba: Fundação de Estudos Agrários "Luiz de Queiroz", 2001. p.314-315.
AMERICAN PUBLIC HEALTH ASSOCIATION - APHA. Standard methods for the examination of water and wastewater. 19.ed. Washington, D.C.: APHA, 1995. 1268p.

ASSOCIATION OF OFFICIAL ANALYTICAL CHEMISTS AOAC. Official methods of analysis. 12.ed. Washington, D.C.: AOAC, 1990. 1298p.

BASTIMAN, B. Factors affecting silage effluent production. Experimental Husbandry, v.31, p.40-46, 1976.

BEAUCHEMIN, K.A.; YANG, W.Z.; RODE, L.M. Effects of fibrolytic enzymes additives on extent of digestion and milk production of lactating cows. Journal of Animal Science, v.76, suppl. 1, p.358, 1998.

BEAUCHEMIN, K.A.; COLOMBATTO, D.; MORGAVI, D.P. et al. Use of exogenous fibrolytic enzymes to improve feed utilization by ruminants. Journal of Animal Science, v.81, E suppl. 2, p.E37-E47, 2002.

BRAILE, P.M.; CAVALCANTE, J.E.W.A. Manual de tratamento de águas residuárias industriais. São Paulo: Companhia de Tecnologia de Saneamento Ambiental, 1993. 764p.

CASTLE, M.E.; WATSON, J.N. The relationship between the DM content of herbage for silage making and effluent production. Journal of the British Grassland Society, v.28, p.135-138, 1973.

COPAM. Legislação ambiental. 3.ed. Belo Horizonte: Imprensa Oficial, 1986. 183p.

DUBOIS, M.K.; GILLES, K.A.; HAMILTON, J.K. et al. Colorimetric method for determination of sugars and related substances. Analytical Chemistry, v.28, p.350-356, 1956.

FEAM. Licenciamento ambiental: Coletânea de legislação. In: Manual de saneamento e proteção ambiental para municípios. Belo Horizonte: FEAM, 1998. 382p.

FENG, P.; HUNT, C.W.; JULIEN, W.E. et al. Effect of enzymes additives on in situ and in vitro degradation of mature coolseason grass forage. Journal of Animal Science, v.70, suppl. 1, p. 309, 1992.

GALANOS, E.; GRAY, K.R.; BIDDLESTONE, A.J. et al. The aerobic treatment of silage effluent: effluent characterization and fermentation. Journal of Agricultural Engineering Research, v.62, p.271-279, 1995.

GREENHILL, W.L. Plant juice in relation to silage fermentation. I The role of the juice. Journal of the British Grassland Society, v.19, p.30-37, 1964.

HAIGH, P.M. Effluent production from grass silage treated with additives and in large-scale bunker silos. Grass and Forage Science, v.54, p.208-218, 1999.

HOLDEN, L.A. Comparison of methods of in vitro dry matter for ten feeds. Journal of Dairy Science, v.82, n.8, p.1791-1794, 1999.

IGARASI, M.S. Controle de perdas na ensilagem de capim Tanzânia (Panicum Maximum Jacq. cv Tanzânia) sob os efeitos do teor de matéria seca, do tamanho de partícula, da estação do ano e da presença do inoculante bacteriano. Piracicaba, 2002. 132p. Dissertação (Mestrado) - Escola Superior de Agricultura "Luiz de Queiroz", Universidade de São Paulo.

JASTER, E.H. Legume and grass silage preservation. In: MOORE, K.J.; KRAL, D.M.; VINEY, M.K. (Eds.) Post-harvest physiology and preservation of forage. Madison: ASA, CCSA, 1995. p.91-115.

JONES, D.I.H.; JONES, R. The effect of crop characteristics and ensiling methodology on grass silage effluent production. Journal of Agricultural Engineering Research, v.60, p.73-81, 1995. 
JUNG H. G.; ALLEN, S. Characteristics of plant cell walls affecting intake and digestibility of forages by ruminants Journal of Animal Science, v.73, p.2774-2790, 1995.

KRAUS, T.J.; KOEGEL, R.G.; STRAUB, R.J. et al. Leachate conductivity as an index for quantifying level of forage conditioning. In: ASAE ANNUAL INTERNATIONAL MEETING 1997, Minneapolis,. Proceedings... Minneapolis: ASAE, 1997. p.1-12.

KUNG JR., L.; GRIEVE, D.B.; THOMAS, J.W. et al. Added ammonia or microbial inocula for fermentation and nitrogenous compounds of alfalfa ensiled at various percents of dry matter. Journal of Dairy Science, v.67, n.2, p.299-306, 1984.

LAMMERS, B.P.; BUCKMASTER, D.R.; HEINRICHS, J.A simple method for the analysis of particle sizes of forage and total mixed rations. Journal of Dairy Science, v.79, n.5, p.922-928, 1996.

LEVITT, J. Responses of the plants to environmental stress. New York: Academic Press. 1980. 324p.

LEWIS, G.E.; SANCHEZ, W.K.; HUNT, C.W. et al. Effect of directfed fibrolytic enzymes on the lactational performance of dairy cows. Journal of Animal Science, v.82, p.611-617, 1999.

LOURES, D.R.S. Características do efluente e composição químico-bromatológica da silagem sob níveis de compactação e de umidade do capim-elefante (Pennisetum purpureum Schum.) cv. Cameroon. Viçosa, MG: Universidade Federal de Viçosa, 2000. 67p. Dissertação (Mestrado) Universidade Federal de Viçosa, 2000.

LOURES, D.R.S.; GARCIA, R.; PEREIRA, O.G. et al. Características do efluente e composição químico-bromatológica da silagem de capim-elefante sob diferentes níveis de compactação. Revista Brasileira de Zootecnia, v.32, supl. 2, n.6, p.1581-1858, 2003

MAHANNA, B. Troubleshooting silages problems. In: STATE APPLIED NUTRITION CONFERENCE, 4., 1993, West Des Moines. Summary... West Des Moines: Pioneer Hi-bred International Inc., 1993. p.1-21.

MANDEBVU, P.; WEST, J.W.; HATFIELD, R.D. et al. Effect of treating Bermudagrass forages at ensiling with fibrolytic enzymes or microbial inoculant on carbohydrate content of cell walls, concentrations of p-coumaric and ferulic acids, and in situ digestion. Journal of Dairy Science, v.76, suppl. 1, p.198, 1998.

MANDEBVU, P.; WEST, J.W.; FROETSCHEL, M.A. et al. Effect of enzymes or microbial treatment of bermudagrass forages before ensiling on cell wall composition, end products of silage fermentation and in situ digestion kinetics. Animal Feed Science and Technology, v.77, p.317-329, 1999.

McDONALD, P.; HENDERSON, A.R.; HERON, S.J.E. The biochemistry of silage. 2. ed. Marlow: Chalcombe, 1991. 340p.

MUCK, R.E.; KUNG JR., L. Effects of silages additives on ensiling. In: THE SILAGE: FIELD TO FEED BUNK NORTH AMERICAN CONFERENCE, 1997, Hershey. Proceedings... Hershey: National Regional Agricultural Engineering Service. 1997. p.187-199.
MOSER, L.E. Post-harvest physiological change in forage plants. In: MOORE, K.K; KRAL, D.M.;VINEY, M.K. (Eds.). Postharvest physiology and preservation of forages. Madison: American Society of Agronomy, 1995. p.1-19.

MADEAU, E.M.G.; BUXTON, D.R.; RUSSELL, J.R. et al. Enzyme, bacterial inoculant, and formic acid effects on silage composition of orchardgrass and alfalfa. Journal of Dairy Science, v.83, p.1487-1502, 2000.

NUSSIO, L.G.; HUBER, J.T.; THEURER, C.B. et al. Influence of a cellulase/xylanase complex $(\mathrm{C} / \mathrm{X})$ on lactational performance of dairy cows fed alfalfa hay (AH) based diets. Journal of Dairy Science, v.80, suppl. 1, p.220, 1997.

NUSSIO, L.G.; PAZIANI, S.F.; NUSSIO, C.M.B. Ensilagem de capins tropicais. In: REUNIÃO ANUAL DA SOCIEDADE BRASILEIRA DE ZOOTECNIA, 2002, 39., Recife. Anais... Recife: Sociedade Brasileira de Zootecnia, 2002. p.60-83.

O'DONNELL, C.; WILLIAMS, A.G.; BIDDLESTONE, A.J. The effects of pressure and stage of ensilage on the mechanical properties and effluent production potential of grass silage. Grass and Forage Science, v.52, p.12-26, 1997

OKUDA, H.; FUGI, S.; KAWASHIMA. A direct colorimetric method for blood ammonia. Journal of Experimental Medicine, v.12, n.1, p.11-23,1965.

PITT, R.E.; PARLANGE, J.Y. Effluent production from silage with application to tower silos. Transactions of the American Society of Agricultural Engineers, v.30, p.1198-1204. 1987.

ROTZ, C.A.; PITT, R.E.; MUCK, E.M. et al. Direct-cut harvest and storage of alfalfa on the dairy farm. Transactions of the American Society of Agricultural Engineers, v.36, n.3, p.621-628, 1993.

STATISTICAL ANALYSES SYSTEM - SAS. SAS/STAT. User's Guide. Version 8. Cary: 2000.

SILVA, D.J. Análise de alimentos: métodos químicos e biológicos. Viçosa, MG: Universidade Federal de Viçosa, 1990. 165p.

SILVA, M.O.S.A. Análises físico-químicas para controle de estação de tratamentos de esgotos. São Paulo: CETESB, 1977. $266 \mathrm{p}$.

Van SOEST, P.J.; ROBERTSON, J.B.; LEWIS, B.A. Methods for dietary fiber, neutral detergent fiber, and non-starch polysaccharides in relation to animal nutrition. Journal of Dairy Science, v.74, p.3583-3597, 1991.

Van SOEST, P.J. Nutritional ecology of the ruminants. Ithaca: Cornell University, 1994. 476p.

WILES. P.G.; GRAY, I.K ; KISSLING, R.C. Routine analysis of protein by Kjeldahl and Dumas methods: review and interlaboratory study using dairy products. Journal of AOAC International, v.81, n.3, p.620-632, 1998

WOOLFORD, M.K. The silage fermentation. New York: Marcel Dekker, 1984. 322p.

Recebido em: 12/02/04 Aceito em: 13/04/05 